\title{
Endo-parasites of public-health importance recovered from rodents in the Durban metropolitan area, South Africa
}

\author{
Colleen E Archera*, Christopher C Appleton ${ }^{\mathrm{a}}$, Samson Mukaratirwa ${ }^{\mathrm{a}}$, Jennifer Lamb ${ }^{\mathrm{a}}$ and M Corrie Schoeman \\ aSchool of Life Sciences, College of Agriculture, Engineering \& Science, University of KwaZulu-Natal, Durban, South Africa \\ *Corresponding author, emails: archerc@ukzn.ac.za, archerc56@gmail.com
}

Background: Parasite infections of public health importance carried by Rattus spp. on the African continent (excluding toxoplasmosis) have not been adequately researched. The aim of this study was to investigate endoparasites of public health importance, particularly those associated with R. norvegicus, at different locations and seasons within the port-city, Durban. Methods: Four hundred rodents (379 R. norvegicus, 10 R. rattus and 11 Mastomys natalensis) were live-trapped at 60 sites in four locations, during wet and dry seasons in 2009. Rats were humanely euthanased, cardiac blood drawn (for blood smears and serology), ectoparasites removed and dissected. Each organ was separately processed to collect parasites. Binary logistic regression and four-way ANOVAs were used to test for the effects of location, season, rodent age and gender on parasite prevalence, richness and abundance.

Results: Eight parasites of public health importance were detected: Gongylonema sp. (25.3\%), Trypanosoma lewisi (22.8\%), Hymenolepis diminuta (17.2\%), Angiostrongylus cantonensis (15.3\%), Toxoplasma gondii (11.2\%), Moniliformis moniliformis (9.5\%), Calodium hepaticum (2.6\%) and H. nana (0.8\%). Ascaris spp. (probably A. lumbricoides) ova, assumed to have been acquired from consuming infected human faeces were found in rat faeces (4.8\%). Parasite species richness was positively associated with location, season and rodent age. Location, season, rat age and gender differentially affected prevalence and worm abundance of parasite species.

Conclusions: These occurrence data of parasites of public health importance provide valuable information to local and provincial organisations and medical practitioners for diagnoses of possible zoonoses, and a reference point for further studies in metropolitan areas of Africa.

Keywords: helminths, parasites, protozoa, public health, Rattus norvegicus, rodents, zoonoses

\section{Background}

Maritime trade dates back at least two millennia and linked Asia to Europe and West Africa. ${ }^{1}$ Rattus rattus and $R$. norvegicus, both natives of Asia, probably began their global spread along these trade routes and were also likely the cause of the three major pandemics of plague since the 6th century. The factors responsible for rodents co-habiting with humans have remained the same for many centuries, viz. harbourage, ${ }^{2}$ lack of a sanitary environment ${ }^{3}$ and availability of food. ${ }^{4}$ Since the 15 th century, trade routes have expanded globally. For example, $>4500$ commercial vessels dock in Durban in eThekwini metropolitan area, South Africa (the 10th largest in the world) every year. ${ }^{3}$ Shipping has consequently facilitated the spread of rats and their cosmopolitan parasites and diseases to people across the globe.

The world's urban population is expected to rise by 2.1 billion by 2030. ${ }^{3}$ Durban, along with most cities in developing countries, has seen a considerable shift from rural to city dwellers. This influx of people into cities has resulted in the proliferation of informal housing, illegal occupation of dwellings and degradation of formal housing due to low socioeconomic conditions which, in turn, has favoured the breeding of rats. ${ }^{5}$ For example, in Johannesburg, South Africa, more rats were reported from: informal dwellings than from apartments; homes where occupants did not pay rent than houses where rent was paid or homes were owned; houses with cracks, leaks, dampness, mould and crowding and where waste collection by the municipality was "never" than well-maintained brick homes with daily or weekly waste collection; and households with no income compared to those with an income of $>$ ZAR 5000 ( \pm US\$ 320) per month. ${ }^{5}$ Because rodents scavenge for food and are coprophagous, they are at risk of ingesting infective agents of disease, e.g. parasite eggs and insects (or their faeces). Furthermore, many intermediate hosts of diseases that rats host (such as fleas and ticks) and their endoparasites contaminate human food stores. ${ }^{6}$ Hence, zoonotic infections in urban-dwelling humans are probably increasing. Furthermore, mechanical spread of parasites by rats may pose a particularly high risk for disease transmission in slums and informal settlements in urban and peri-urban areas where humans practice open defaecation and foraging animals live and wander freely. ${ }^{6}$

Parasites of Rattus spp. from across the globe have been described in the literature for more than a century, ${ }^{7-10}$ yet relatively few studies investigated the influence of location, season, rodent age and gender on endoparasite prevalence and diversity. ${ }^{11}$ Moreover, comprehensive studies on parasites of Rattus spp. from Africa are scant, and limited to reports of select gastrointestinal tract (GIT) parasites ${ }^{12}$ or zoonoses. ${ }^{13}$ Specifically, a decade ago, two zoonotic parasites, Hymenolepis diminuta and $H$. nana were found in R. norvegicus in Durban, and serological testing revealed that $4.1 \%$ of $R$. norvegicus and $35 \%$ of human inhabitants of an informal settlement had antibodies to Toxoplasma gondii. ${ }^{14}$

The aim of this study was to therefore investigate the occurrence and distribution of endoparasites of public health importance, particularly those associated with rodents, within the eThekwini metropolitan area, South Africa. Other parasites found will be dealt with elsewhere, and ectoparasites from these rodents were reported by Hope (2011). ${ }^{15}$ We gauged the influence of location, season, age and gender of rodents on parasite prevalence, 
abundance and richness. Finally, we assessed risk factors for rat to human disease transmission in the urban landscape.

\section{Methods}

\section{Study locations and seasons}

To capture rats across the eThekwini metropolitan area, the study area was divided into four locality types, namely: central business district (CBD), harbour (HBR), informal settlements/slums (IS) and urban/peri-urban (U/PU) (Figure 1). There were 60 collection sites across these four locations. The CBD and HBR were characterised by many closely juxtaposed buildings, heavy human traffic and widespread food trade, whereas IS was characterised by slums, informal settlements and low-cost housing developments, and U/ PU by formal setllements (i.e. houses and apartments), de-centralised shopping areas, recreational and small-wildlife parks, small poultry farms, and wastewater treatment works. The study spanned one year to allow for seasonal variations. There were two distinct periods of rainfall: five wet months (January, February, October, November and December) and seven dry months (March to September). Climate data were provided by weather-station number 461, Mount Edgecombe, $29^{\circ} 42^{\prime} 0^{\prime \prime} \mathrm{S}, 31^{\circ} 2^{\prime} 0^{\prime \prime} \mathrm{E}, 96 \mathrm{~m}$ above sea level.

\section{Sampling of rodents}

Ethical approval for this study was granted by the Animal Ethics Committee of the University of KwaZulu-Natal (Ref. 031/09/ Animal) with the proviso that euthanasia was performed by trained mammalogists in accordance with international ethical guidelines. ${ }^{16}$ For logistical and safety reasons, rodents were trapped by eThekwini Health Department's Vector Control
Division. Trapping was largely opportunistic and often done in response to complaints from the public. Custom-made traps resembling the Monarch Rat Trap were used, with bread, vegetables and meat as bait.

Chloroform was used to euthanase each animal before a cardiac puncture was performed to obtain blood. Thin and thick blood smears were made and serum was harvested and frozen for serological tests [plague and leptospirosis by the National Health Laboratory Services (NHLS), Johannesburg, South Africa]. Any remaining sera were returned to our laboratory by NHLS to test for toxoplasmosis antibodies. Thin blood smears were fixed in $100 \%$ methanol and thick smears were air-dried for one hour. The former were stained with May-Grünewald/Giemsa and the latter with Giemsa, ${ }_{17}^{17}$ allowed to dry and then stored in wooden slide boxes until examination.

Rodents were weighed with a Pasola scale (to the nearest $0.5 \mathrm{~g}$ ), gender and breeding status recorded, and selected body measurements taken (to the nearest $0.1 \mathrm{~mm}$ ): total body length (body + tail length), tail length, length of right ear and right hind foot (excluding and including claw). Rodents were then dissected: the diaphragm was removed first, followed by the heart and lungs, the liver, the GIT, the kidneys and bladder and lastly the tongue. Organs (except GIT) were placed into separate jars, covered with digestive medium for tissue $(5 \mathrm{~g}$ pepsin $+7 \mathrm{ml}$ hydrochloric acid, in 1 I distilled water) and incubated at $37^{\circ} \mathrm{C}$ for 12 to $18 \mathrm{~h}$ to free parasites for collection, preservation and identification. The GIT was divided into five sections: oesophagus, stomach, small intestine, caecum and large intestine. Each of these sections was carefully slit open, placed in a jar and covered

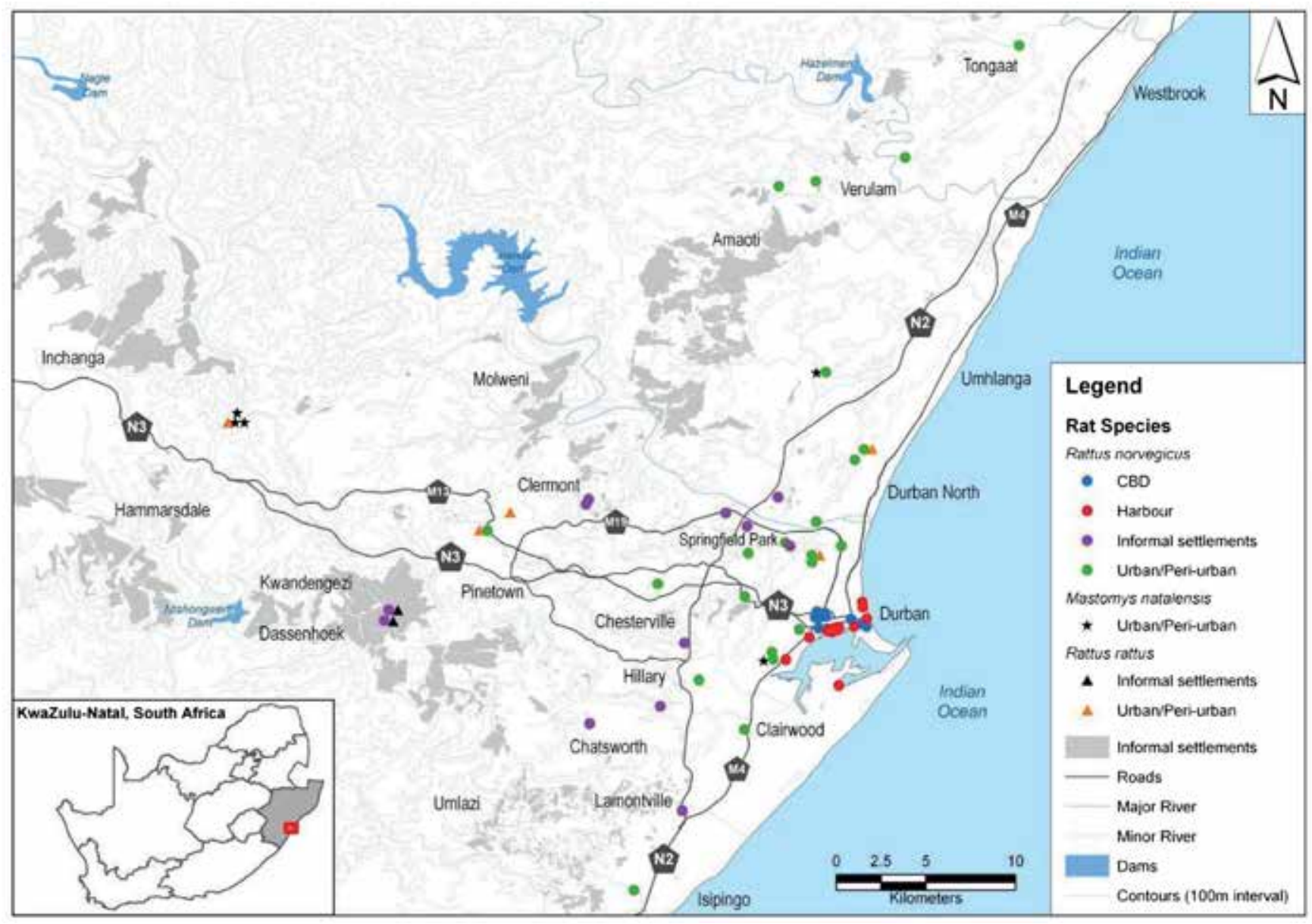

Figure 1: Map of Durban, eThekwini Metro, South Africa, showing study locations and rodents captured. 
with $70 \%$ ethanol to preserve all parasites in that section. All macroscopically visible acanthocephalans, cestodes and nematodes were removed from the small intestine and preserved in $70 \%$ ethanol. Smaller worms of these three helminth taxa and those buried in the mucosa of oesophagus and stomach were removed from each section using a dissecting microscope, identified, counted and placed in $70 \%$ ethanol in separate containers for each host animal.

Faeces excreted during euthanasia or found in the rectum at dissection, were placed in $10 \%$ formal-saline. For rats that had no faecal pellets, a caecal sample was taken and processed as for the faecal pellets. Samples were processed using the modified formal-ether concentration method ${ }^{18}$ to check for helminth eggs and protozoan cysts/oocysts. Adult worms from the caecal subsamples were stored for future work on parasites of no public health importance.

\section{Aging of rodents}

Because the prepatent periods of most parasites are four to six weeks, prevalence of parasites in very young rats (unweaned pups) are likely to differ from weaned juveniles. Thus, $R$. norvegicus were categorised into three age-groups: pups, juveniles and adults. Rattus rattus by-catches were classified into age groups according to Hirata and Nass. ${ }^{19}$ Pups included unweaned rats up to approximately four weeks; juveniles included rats of approximately five to 10 weeks, probably weaned and some sexually mature; and adults were all sexually mature and $>10$ weeks old. Mastomys natalensis are difficult to age yet those $\leq 30 \mathrm{~g}$ typically are juveniles. ${ }^{20}$ In this study, all $M$. natalensis by-catches were adults ( $>30 \mathrm{~g}$ ), hence those $>50 \mathrm{~g}$ were categorised as old adults and those $<50 \mathrm{~g}$ as young adults.

\section{Identification of parasites of zoonotic importance}

\section{Detection of Toxoplasma gondii}

T. gondii infection was determined serologically using the Bio-Rad Pastorex $^{\mathrm{TM}}$ Toxo kit (USA). All weak positives and inconclusive results on initial testing were re-run and confirmed using a second observer. Results were reported as either positive or negative.

\section{Zoonotic protozoans and helminths}

Trypanosoma lewisi, was identified morphologically according to Hoare..$^{21}$ To identify the acanthocephalan, the taxonomic key by Van Cleave, which uses the armament of the proboscis, was followed. ${ }^{22}$ Cestodes were identified based on the morphology of their scolices and eggs. Nematodes in the liver were identified by broken pieces of gravid female worms and characteristic eggs. Nematodes in oesophagus and stomach mucosa were identified to genus by characteristic scutes at anterior end of the body. ${ }^{23}$ Adult nematodes in the heart and its associated vessels and eggs, and L1 larvae in the lungs, were identified using morphological features as described by Macherras and Sandars. ${ }^{24}$

\section{Genetic confirmation of A. cantonensis}

DNA was isolated from tissue samples using a DNeasy ${ }^{\circledR}$ DNA isolation kit (QIAGEN Inc., USA). Analyses were based on the mitochondrial cytochrome oxidase 1 (CO1) gene (primers: LCO (forward) 5' GGTCAACAAATCATAAAGATATTGG and HCO (reverse) 5'-TAAACTTCAGGGTGACCAAAAAATCA) and nuclear ribosomal RNA ITS2 region (primers: NC1 (forward) 5 -ACGTCTGGTTCAGGGTTGTT and NC2 (reverse) 5'-TTAGTTTCTTTTCCTCCGCT). PCR amplifications were performed in $25 \mu \mathrm{l}$ volumes. Each reaction contained $0.8 \mu \mathrm{l}$ sterile water, $2.5 \mu \mathrm{l} 10 \mathrm{X}$ reaction buffer (SuperTherm, UK), $4 \mu \mathrm{l}$
$25 \mathrm{mM} \mathrm{MgCl}$ (SuperTherm, UK), $0.5 \mu \mathrm{l} 10 \mathrm{mM}$ deoxynucleosidetriphosphate mixture (dNTPs) (Roche Diagnostics, Switzerland), $0.2 \mu \mathrm{l}$ Taq polymerase $(5 \mathrm{U} / \mu \mathrm{l})$ (SuperTherm, UK) and $4 \mu \mathrm{l}$ of each primer $(6 \mu \mathrm{M})$ (forward and reverse) per reaction. The thermal cycling parameters used were as follows: $\mathrm{CO} 1-94^{\circ} \mathrm{C}$ for 4 min, followed by 40 cycles of $\left(95^{\circ} \mathrm{C}\right.$ for $1 \mathrm{~min}, 50^{\circ} \mathrm{C}$ for $1 \mathrm{~min}$ and $72^{\circ} \mathrm{C}$ for $2 \mathrm{~min}$ ) and followed by $72{ }^{\circ} \mathrm{C}$ for $10 \mathrm{~min}$; ITS2 $-95{ }^{\circ} \mathrm{C}$ for $5 \mathrm{~min}$, followed by 40 cycles of $\left(95^{\circ} \mathrm{C}\right.$ for $1 \mathrm{~min}, 58^{\circ} \mathrm{C}$ for $1 \mathrm{~min}$ and $72{ }^{\circ} \mathrm{C}$ for $90 \mathrm{~s}$ ) and followed by $72{ }^{\circ} \mathrm{C}$ for $10 \mathrm{~min}$.

Target fragments were purified from excised gel bands using the QIAquick ${ }^{\circledR}$ Gel Extraction Kit (QIAGEN Inc., USA) and sequenced at InqabaBiotec, South Africa. All fragments were sequenced in both directions to allow reconciliation of ambiguous positions. They were aligned using the CLUSTAL W option ${ }^{25}$ of the BioEdit program (ver. 5.0.9 for Windows 95/98/NT) and by visual inspection. Similar sequences were identified by BLAST searches of the NCBI GenBank and downloaded for inclusion in the analyses. For the ITS analysis, the following GenBank sequences were included: Angiostrongylus catonensis EU636007, GQ18112, HQ540543, HQ540544, HQ540547; Angiostrongylus daskalovi KX242346; Angiostrongylus vasorum EU627592, EU627593 - EU627596; outgroups Aelurostrongylus abstrusus DQ372965 and JX948745. Sequences used in the CO1 analysis were: Angiostrongylus catonensis GQ398121, KT947978; Angiostrongylus malayensis KT947979; Angiostrongylus vasorum GQ982872, JX268542; Angiostrongylus costaricensis KR827449, GQ398122; outgroups Caenorhabditis briggsiae EU407785 and Dictyocaulus viviparous JX519460.

Trees were constructed using the neighbour-joining and parsimony methods in PAUP 4.0b10. ${ }^{26}$ The software jModelTest 0.1.1 ${ }^{27}$ was used, applying the AKAIKE information criterion, to determine the most appropriate evolutionary model $(G T R+G)$ to use in neighbour-joining analyses. For parsimony analysis, the addition sequence was random, with one tree held at each step and with ten replicates. A total of 1000 bootstrap replicates were carried out for both parsimony and neighbour-joining analyses.

\section{Examination of faecal pellets for parasite ova}

Helminth eggs and larvae of parasites normally parasitising rats were reported as absent or present on a plus-scale of 1-4. Only eggs from parasites not normally infecting rodents (i.e. those mechanically transmitted via ingestion and excretion) were counted.

\section{Statistical analyses}

Two-way ANOVAs were used to test differences in numbers of $R$. norvegicus captured between location and season. Binary logistic regression was used to identify the most significant predictors - location, season, age and gender - of parasite infection (prevalence). Four-way ANOVAs on the ranked data were used to examine differences in (i) mean worm abundance of zoonotic helminths identified, (ii) mean intensity of trypanosome infections and (iii) species richness, in $R$. norvegicus among location, season, age and gender. All statistical analyses were performed using SPSS (version 23 College Station, Texas, USA).

\section{Results}

\section{Rodents trapped per location and season}

Rattus norvegicus comprised $94.8 \%(n=379)$ of the 400 rodents sampled. Additionally, $10 \mathrm{R}$. rattus and $11 \mathrm{M}$. natalensis were trapped. Numbers of $R$. norvegicus trapped per location were: 101 from CBD, 93 from HBR, 97 from U/PU and 88 from IS. There was a significant difference in number of $R$. norvegicus sampled 


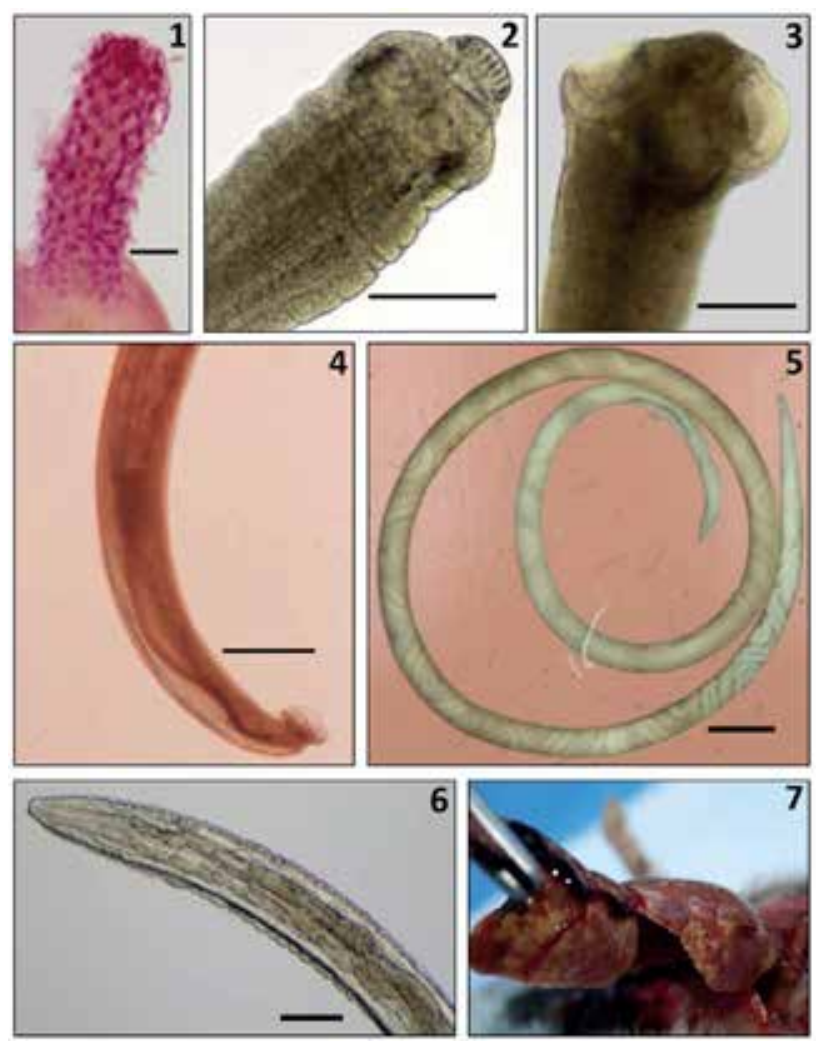

Figure 2: Adult worms and tissue pathology (scale bars $=100 \mu \mathrm{m}$ ) 1: Proboscis of M. moniliformis showing characteristic rows of recurved hooks; 2: H. nana scolex with 4 suckers and raised rostellum armed with hooklets; 3 : H. diminuta scolex showing 4 cup-shaped suckers and unarmed rostellum; 4: Rear end of $A$. cantonensis male worm showing copulatory bursa and long spicules; 5: A. cantonensis female worm with the characteristic "barber's pole" appearance; 6: Gongylonema head end showing characteristic scutes; 7. Liver of male M. natalensis at dissection showing the extent of his $C$. hepaticum infection (yellow lesions in the surface parenchyma).
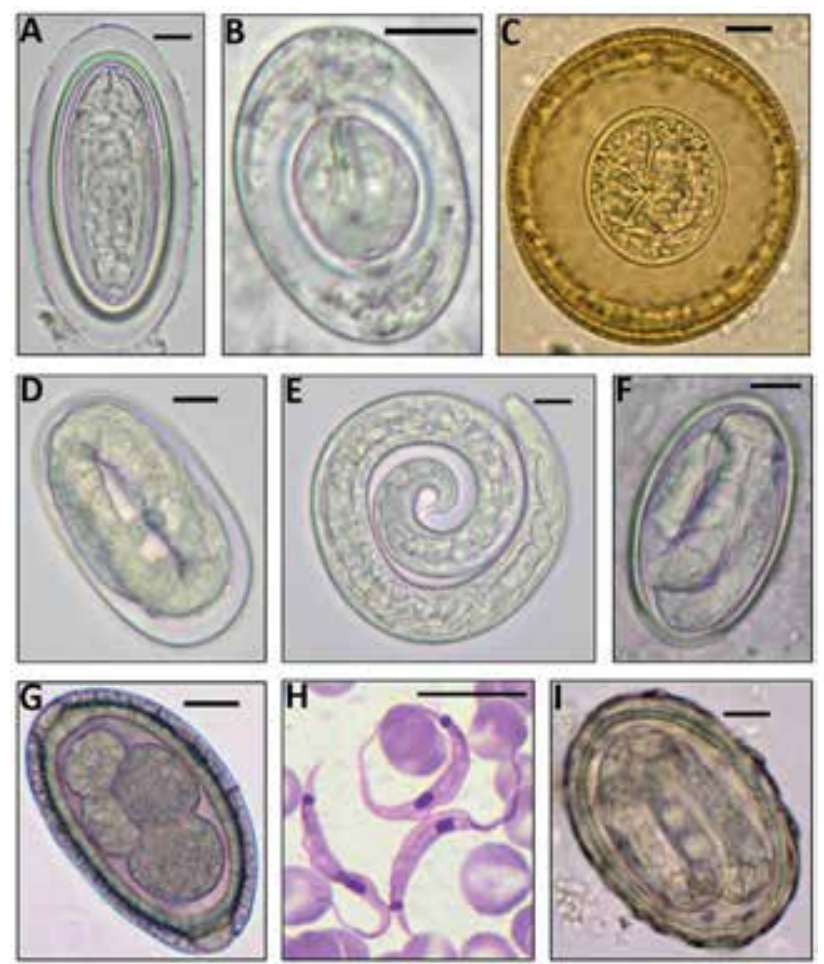

Figure 3: Helminth eggs and larva \& the protozoan blood parasite found (scale bars $=10 \mu \mathrm{m}$ ). A: M. moniliformis egg; B: H. nana egg; C: H. diminuta egg; D: A. cantonensis egg; E: A. cantonensis L1 larva; F: Gongylonema sp. egg; $\mathrm{G}$ : C. hepaticum egg; H: Trypanosoma lewisi trypomastigotes; I: Ascaris sp. egg. among locations and between seasons (2-way ANOVA: $\mathrm{F}_{(7,378)}=$ 22.136; $p<0.001)$. Post-hoc Tukey tests showed that significantly more $R$. norvegicus were trapped at CBD than IS $(p<0.001)$ and $\mathrm{U} / \mathrm{PU}(p=0.001)$. Further, significantly fewer rats were captured during the wet months $(n=137)$ than dry months $(n=242)$ $(p<0.001)$. Abundance of $R$. norvegicus was highest in September $(n=75)$ and lowest in December $(n=2)$. Rattus rattus and $M$. natalensis were captured only at U/PU ( $n=8$ and 11, respectively; in both seasons) and IS [2 R. rattus (in both seasons) and $1 \mathrm{M}$. natalensis (in dry season only)].

\section{Parasites of public health importance}

Patent infections of Trypanosoma lewisi (Protista), M. moniliformis (Acanthocephala), H. diminuta and $H$. nana (Cestoda); Gongylonema sp., A. cantonensis and C. hepaticum (Nematoda), were found in R. norvegicus (Figures 2 and 3), while $T$. gondii (Protista) was confirmed serologically. Rattus rattus harboured only $T$. gondii, $H$. diminuta and $A$. cantonensis, and $M$. natalensis was infected with $H$. diminuta, C. hepaticum (Figure 2) and Angiostrongylus cantonensis.
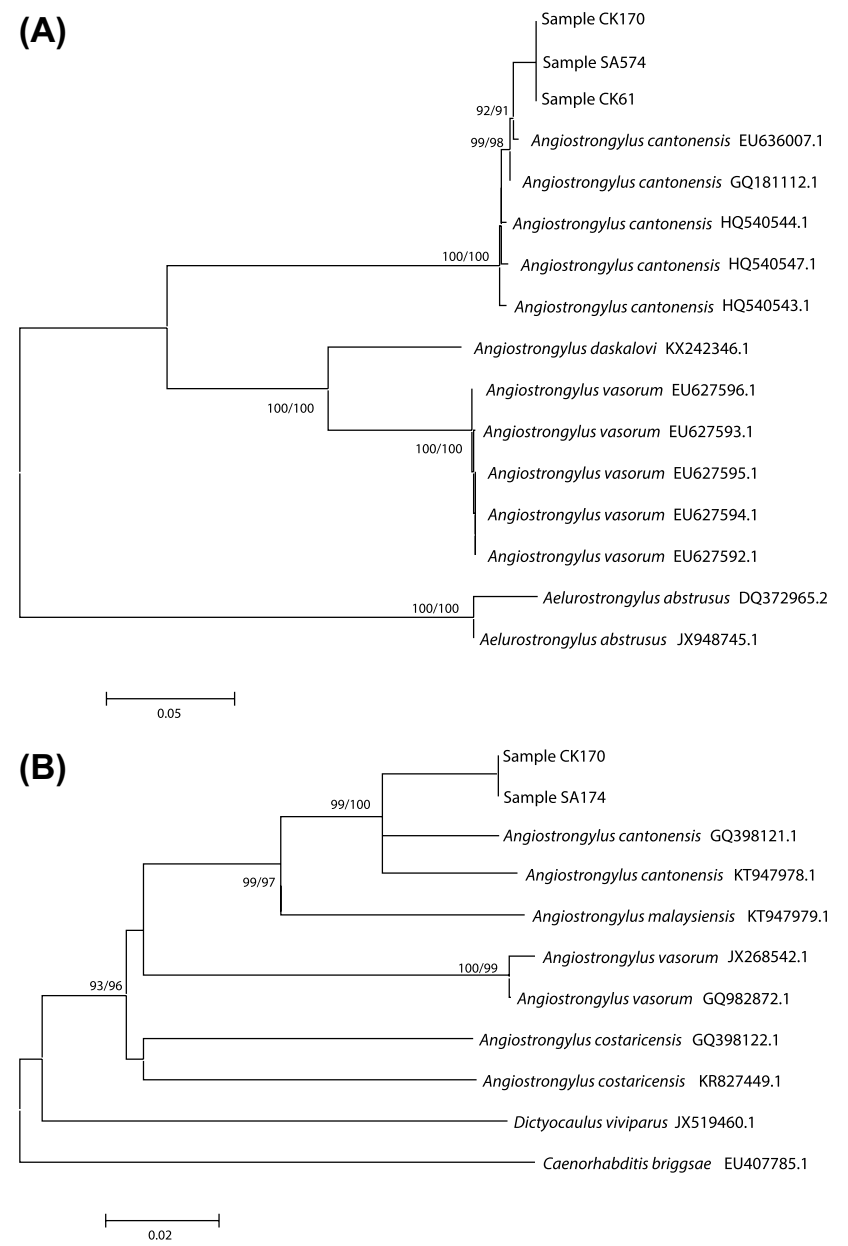

Figure 4: (A) Neighbour-joining tree based on 367 nucleotides of the nuclear ribosomal ITS2 DNA region illustrating relationships between experimental samples CK61, CK170 and SA574, Angiostrongylus sequences downloaded from the GenBank, and the outgroups Aleurostrongylus abstrusus. Bootstrap support for nodes is given as $[\mathrm{nj} \% / \mathrm{p} \%]$ for neighbour-joining ( $\mathrm{nj}$ ) and congruent parsimony(p) analyses and (B) Neighbour-joining tree based on 611 nucleotides of the mitochondrial cytochrome oxidase 1 gene illustrating relationships between experimental samples CK170 and SA574, Angiostrongylus sequences downloaded from the GenBank, and the outgroups Dictyocaulus viviparous and Caenorhabditis briggsae. Bootstrap support for nodes is given as [nj\%/p\%] for neighbour-joining ( $\mathrm{nj}$ ) and congruent parsimony $(p)$ analyses. 
The CO1 and ITS2 alignments were trimmed to 611 and 367 nucleotides, respectively, and used in further analyses. Analyses based on both the $\mathrm{CO} 1$ and ITS2 regions (Figures $4(\mathrm{~A})$ and (B)) were congruent and indicated that the experimental samples were previously unreported haplotypes of Angiostrongylus cantonensis. This is based on the inclusion of the experimental samples in a very stongly supported clade (99-100\% bootstrap support) which included GenBank samples of $A$. cantonensis. This enabled the experimental samples to be referred to $A$. cantonensis according to the phylogenetic species concept. ${ }^{28}$

No adult worms were found in some $R$. norvegicus although eggs of $M$. moniliformis, $H$. diminuta and Gongylonema sp. and L1 larvae of $A$. cantonensis were detected in the faeces. Other eggs found were: Calodium hepaticum (ingested via environmental contamination or through necrophagy), Taenia sp., Schistosoma mansoni and Ascaris sp. (for which rats are not natural hosts). Toxocara sp. ova were found in the faeces of one $R$. rattus individual and C. hepaticum ova were found in the faeces of the same $M$. natalensis that harboured a patent $C$. hepaticum infection. This was considered as mechanical transmission (meaning: 'the transmitter is not infected in that tissues are not invaded and the agent does not multiply'). ${ }^{29}$ Ova of Moniliformis moniliformis, H. diminuta, and Gongylonema sp., and L1 larvae of A. cantonensis were mechanically transported by seven, 51,11 and seven $R$. norvegicus, respectively.

Most of the helminth eggs of public health importance that did not infect rodents, but were mechanically transported by them, were the roundworm Ascaris sp., probably A. lumbricoides (Figure 3). These eggs were present in the gut contents of 20 rats: three rats in U/PU (range of 1-6 eggs/rat); four rats in CBD (1 egg each); and 13 in IS (range of 2 - 287 eggs/rat).

\section{Influence of location, season, rodent age and gender on parasite prevalence, richness and abundance}

Because of low sample sizes, endoparasite infections in Rattus rattus and $M$. natalensis were not statistically compared with those in R. norvegicus.

Hosmer and Lemeshow's Goodness of Fit Test was satisfied for logistic models of T. gondii, T. lewisi, M. moniliformis, Gongylonema sp. and $A$. cantonensis, but not for $H$. diminuta.

\section{Sero-prevalence of T. gondii}

Prevalence of $T$. gondii among $R$. norvegicus was $11.3 \%$ ( $n=$ $14 / 124)$ and among $R$. rattus it was $12.5 \%(n=1 / 8)$. In terms of age groups, $16 \%(n=4 / 25)$ were pups, $6.1 \%(n=3 / 49)$ were juveniles and $14.0 \%(n=7 / 50)$ were adults. No M. natalensis $(n=$ 5) tested positive. Logistic regression showed that location, season, rat age and gender, were not significant predictors for $T$. gondii prevalence (all $p>0.05$ ).

\section{Patent helminth infections}

Gongylonema sp. was found in $25.3 \%$ of $R$. norvegicus ( $n=$ $96 / 379$ ), but was absent from the other two rodent species. This nematode was more prevalent in HBR and CBD than in IS and U/ PU (Table 1, Figure 5). Prevalence increased with the age of rats (Table 1). Mean worm abundance was highest in HBR and CBD and lowest in IS, and it increased with the age of rats, particularly in the wet season (Table 2).
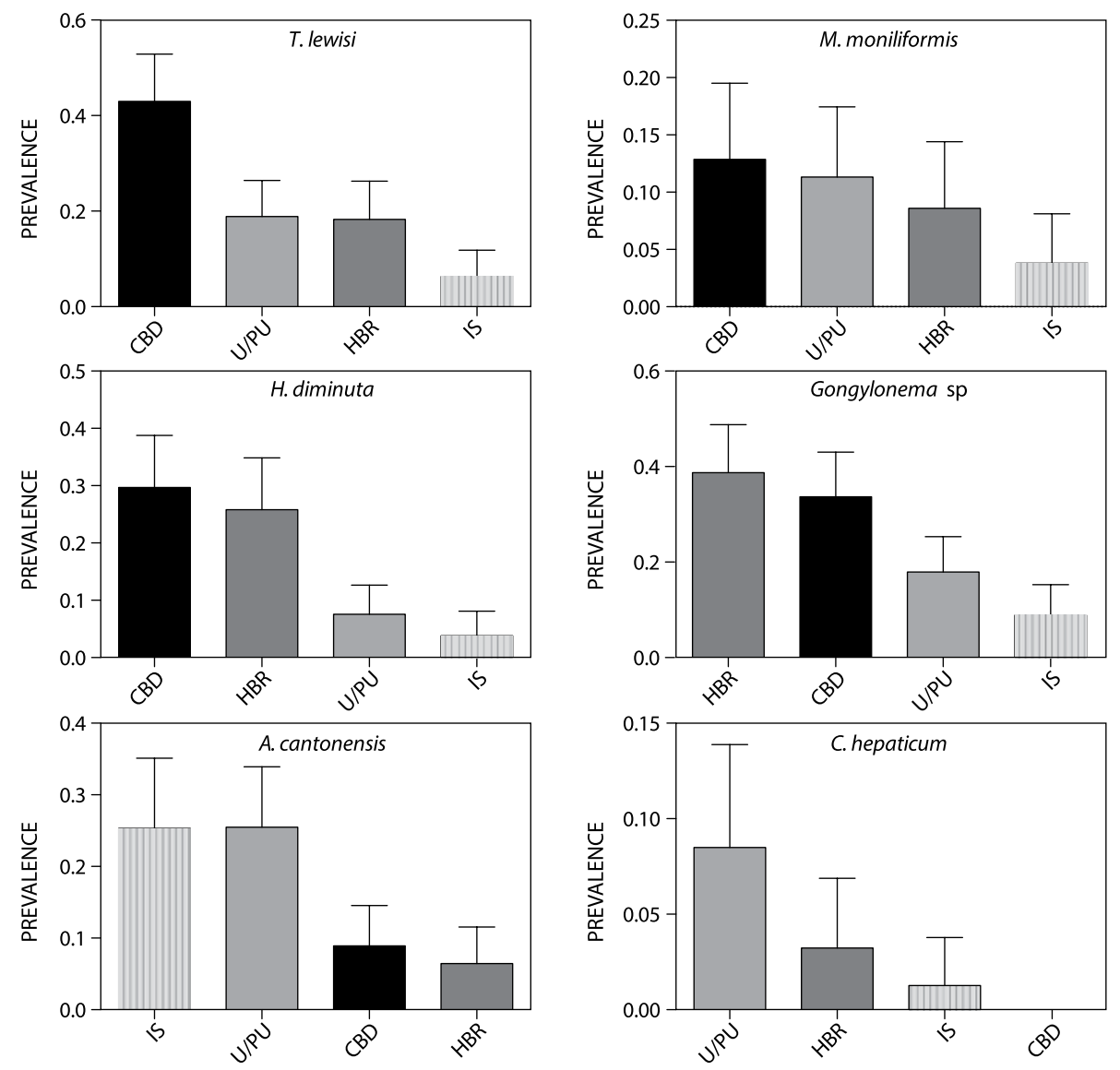

Figure 5: Prevalence (Mean $\pm 95 \% \mathrm{Cl}$ ) of T. lewisi, M. moniliformis, H. diminuta, A. cantonensis, Gongylonema sp., and C. hepaticum in R. norvegicus across 4 locations (CBD = central business district; HBR = harbour; IS = informal settlements; U/PU = urban/peri-urban areas) in Durban. 
Table 1: Significant statistical results for binary logistic regression testing the influence of age and gender of Rattus norvegicus, location and season on prevalence of endoparasites

\begin{tabular}{|c|c|c|c|c|c|c|}
\hline Parasite & $\chi^{2}$ & $d f$ & $p$-value & Variable & Significant variables & $p$-value \\
\hline \multirow[t]{5}{*}{ T. lewisi } & 41.764 & 7 & $<0.001$ & & & \\
\hline & & & & Location & ${ }^{1} \mathrm{CBD}>\mathrm{IS}$ by $6.45 \mathrm{x}$ & $<0.001$ \\
\hline & & & & & CBD $>$ HBR by $3.40 x$ & 0.001 \\
\hline & & & & & $\mathrm{CBD}>\mathrm{U} / \mathrm{PU}$ by $3.56 \mathrm{x}$ & $<0.001$ \\
\hline & & & & Age & J $>A$ by $2.85 x$ & 0.003 \\
\hline \multirow[t]{3}{*}{ M. moniliformis } & 15.556 & 7 & 0.029 & & & \\
\hline & & & & Age & $A>P$ by $3.85 x$ & 0.024 \\
\hline & & & & & $A>$ J by $2.93 x$ & 0.020 \\
\hline \multirow[t]{9}{*}{ H. diminuta } & 74.685 & 7 & $<0.001$ & & & \\
\hline & & & & Location & $\mathrm{CBD}>\mathrm{HBR}$ by $2.20 \mathrm{x}$ & 0.033 \\
\hline & & & & & $\mathrm{CBD}>\mathrm{IS}$ by $13.00 \mathrm{x}$ & $<0.001$ \\
\hline & & & & & $\mathrm{CBD}>\mathrm{U} / \mathrm{PU}$ by $5.86 \mathrm{x}$ & $<0.001$ \\
\hline & & & & & $\mathrm{HBR}>\mathrm{IS}$ by $5.89 \mathrm{x}$ & 0.007 \\
\hline & & & & & $\mathrm{HBR}>\mathrm{U} / \mathrm{PU}$ by $2.65 \mathrm{x}$ & 0.036 \\
\hline & & & & Season & Wet $>$ Dry by $3.35 x$ & $<0.001$ \\
\hline & & & & Age & $A>P$ by $6.51 x$ & 0.002 \\
\hline & & & & & $J>P$ by $8.25 x$ & $<0.001$ \\
\hline \multirow[t]{8}{*}{ Gongylonema sp. } & 68.553 & 7 & $<0.001$ & & & \\
\hline & & & & Location & $\mathrm{CBD}>\mathrm{IS}$ by $5.67 \mathrm{x}$ & $<0.001$ \\
\hline & & & & & $\mathrm{HBR}>\mathrm{IS}$ by $6.82 \mathrm{x}$ & $<0.001$ \\
\hline & & & & & $\mathrm{CBD}>\mathrm{U} / \mathrm{PU}$ by $2.70 \mathrm{x}$ & 0.008 \\
\hline & & & & & $\mathrm{HBR}>\mathrm{U} / \mathrm{PU}$ by $3.25 \mathrm{x}$ & 0.002 \\
\hline & & & & Age & $A>P$ by $10.89 x$ & $<0.001$ \\
\hline & & & & & $A>$ J by $3.11 x$ & $<0.001$ \\
\hline & & & & & $\mathrm{J}>\mathrm{P}$ by $3.50 \mathrm{x}$ & 0.006 \\
\hline \multirow[t]{7}{*}{ A. cantonensis } & 93.376 & 7 & $<0.001$ & & & \\
\hline & & & & Location & IS > HBR by $9.93 x$ & $<0.001$ \\
\hline & & & & & $\mathrm{U} / \mathrm{PU}>\mathrm{HBR}$ by $6.50 \mathrm{x}$ & $<0.001$ \\
\hline & & & & Season & Wet $>$ Dry by $2.29 \mathrm{x}$ & 0.026 \\
\hline & & & & Age & A $>$ J by $5.55 \mathrm{x}$ & $<0.001$ \\
\hline & & & & & $J>P$ by $19.09 x$ & 0.006 \\
\hline & & & & & $A>P$ by $105.85 x$ & $<0.001$ \\
\hline
\end{tabular}

Notes: $\mathrm{A}=$ adults; $\mathrm{J}=$ juveniles; $\mathrm{P}=$ pups; $\mathrm{CBD}=$ central business district; $\mathrm{HBR}=$ harbour; $\mathrm{IS}=$ informal settlements; $\mathrm{U} / \mathrm{PU}=$ urban/peri-urban areas. 'Example of how to read 'Significant variables' column: 'CBD > IS by $6.4 x^{\prime}$ means rats in CBD are $6.4 x$ more likely to be infected than rats in IS.

Prevalence of Trypanosoma lewisi was $22.8 \%(n=86 / 378)$, and was highest in $\mathrm{CBD}$ and juveniles (Table 1). Mean intensity of infection was affected by location, age and gender (Table 2).

Prevalence of H. diminuta in R. norvegicus was $17.2 \%(n=65 / 379$; Figure 5), in R. rattus, 30\% ( $n=3 / 10)$ and in M. natalensis, $36.4 \%$ $(n=4 / 11)$. $R$. rattus positives were from U/PU. One juvenile (dry season) was infected with six $H$. diminuta and two adults (wet season) with two $H$. diminuta each. Positive $M$. natalensis were adults and from U/PU, three that were caught in the dry season harboured three, eight and two $H$. diminuta, respectively, and one caught in the wet season harboured six worms. Location, season and rat age were significant predictors of $H$. diminuta prevalence and abundance in $R$. norvegicus (Tables 1 and 2). Prevalence was significantly higher at CBD and HBR than at IS and U/PU (Figure 5); in the wet than in the dry season; and in adults and juveniles than in pups. Highest abundances were found in juveniles at HBR and U/PU and in adults at HBR. Juveniles had high mean worm burdens in both seasons, yet adults had high mean worm burdens principally in the wet season. The few infected pups had very low worm burdens.

Prevalence of $A$. cantonensis was $15.0 \%(n=57 / 379)$ in $R$. norvegicus and $10 \%(n=1 / 10)$ in $R$. rattus. The two M. natalensis (18.2\%; $n=2 / 11$ ) infections were possibly $A$. sandarsae given that this species was previously recorded from Mastomys natalensis in Kenya $^{30}$ and Mozambique. ${ }^{31}$ Location, season and age were significant predictors for $A$. cantonensis prevalence in $R$. norvegicus (Table 1 ) - prevalence was significantly higher at IS and U/PU than HBR (Figure 5), in the wet season than dry season, in adults than juveniles and pups, and in juveniles than pups.

Mean worm abundance of $A$. cantonensis was significantly influenced by location, season and age as well as interactions between location and season, location and age, and season, age and gender (Table 2). Highest worm abundance was at IS and U/ 
Table 2: Significant statistical results for 4-way ANOVAs testing differences in trypanosome intensity of infection, worm abundance and species richness between locations and seasons and among age groups and gender of $R$. norvegicus

\begin{tabular}{|c|c|c|c|c|}
\hline $\begin{array}{l}\text { Parasite/Spp. } \\
\text { Richness }\end{array}$ & $\mathbf{F}_{(d f)}$ & $p$-value & $\begin{array}{l}\text { Significant } \\
\text { variables }\end{array}$ & $p$-value \\
\hline \multirow[t]{5}{*}{ T. lewisi } & $F_{(46,363)}=2.166$ & $<0.001$ & & \\
\hline & & & Location & $<0.001$ \\
\hline & & & Age & 0.016 \\
\hline & & & Location*Age & 0.022 \\
\hline & & & Location*Gender & 0.046 \\
\hline \multirow[t]{2}{*}{ M. moniliformis } & $F_{(46,364)}=1.411$ & 0.048 & & \\
\hline & & & Location*Season & 0.046 \\
\hline \multirow[t]{5}{*}{ H. diminuta } & $F_{(46,364)}=3.848$ & $<0.001$ & & \\
\hline & & & Location & $<0.001$ \\
\hline & & & Age & 0.001 \\
\hline & & & Location*Age & 0.001 \\
\hline & & & Season*Age & 0.021 \\
\hline \multirow[t]{3}{*}{ Gongylonema sp. } & $F_{(46,364)}=2.085$ & $<0.001$ & & \\
\hline & & & Location & $<0.001$ \\
\hline & & & Age*Season & 0.018 \\
\hline \multirow[t]{7}{*}{ A. cantonensis } & $F_{(46,364)}=4.939$ & $<0.001$ & & \\
\hline & & & Location & $<0.001$ \\
\hline & & & Season & 0.007 \\
\hline & & & Age & $<0.001$ \\
\hline & & & Location*Season & 0.001 \\
\hline & & & Location*Age & $<0.001$ \\
\hline & & & $\begin{array}{l}\text { Season*Age* } \\
\text { Gender }\end{array}$ & 0.010 \\
\hline \multirow[t]{3}{*}{ Species richness } & $F_{(46,364)}=2.895$ & $<0.001$ & & \\
\hline & & & Location & $<0.001$ \\
\hline & & & Age & $<0.001$ \\
\hline
\end{tabular}

PU in the wet season (alone and combined). Juveniles had the highest worm abundance in U/PU and juveniles and adults had the highest worm abundance in the wet season. Male adult rats in the wet season had the highest mean worm abundance.

Prevalence of $M$. moniliformis in R. norvegicus was $9.5 \%$ ( $n=$ 36/379; Figure 5). Neither R. rattus nor M. natalensis were infected. The only significant predictor for M. moniliformis prevalence was age; prevalence was significantly higher in adults than in juveniles and pups (Table 1). Mean worm abundance was significantly influenced by the interaction of location and season (Table 2) where the highest mean worm abundance was during the wet season at HBR and IS.

Calodium hepaticum prevalence in $R$. norvegicus was $2.6 \%$ $(n=10)$, viz.:

(1) HBR: one juvenile male trapped in the wet season had only C. hepaticum eggs in its liver. Fragments of a single worm were recovered from the liver of one juvenile male rat (dry season). One adult female (dry season) harboured a damaged female worm with eggs and her liver had characteristic creamy-yellow tracks visible on the surface.
(2) U/PU (dry season only): fragments of worms and eggs were recovered from the livers of one juvenile male rat, two adult females and four adult males.

No $R$. rattus were infected and only one adult male $M$. natalensis (prevalence 9.1\%), trapped in the dry season at U/PU was positive. This mouse was the most heavily infected animal trapped and its liver parenchyma showed many yellow lesions (Figure 2), fragments of male and female worms and thousands of eggs. He also passed C. hepaticum eggs in his faeces (unrelated to his own infection) (Figure 3).

Hymenolepis nana was recovered from three $R$. norvegicus only at HBR in the wet season. One pup had 49 worms (prevalence $0.9 \%$ ), one juvenile had eight worms (co-infected with $H$. diminuta; prevalence $0.7 \%$ ), and one adult had a single worm (prevalence $0.8 \%$ ). No H. nana infections were found in the other two rodent species.

\section{Species richness}

The model for species richness was significant for location, season and age (as independent effects). Multiple infections were significantly low at IS and in the dry season and increased with age of rats (Table 2).

\section{Discussion}

This study is the first detailed account of endoparasites of public health importance from urban rats, principally Rattus norvegicus, in Africa. Similar to previous studies in eThekwini, ${ }^{3} R$. norvegicus was the most common rodent sampled (94.8\% of the total catch) and it harboured eight zoonoses. Globally, this rodent species often occurs with other Rattus species and is not always the dominant species, especially in Asia. ${ }^{9}$ The eight parasite species of public health importance are cosmopolitan. ${ }^{32}$ Location, season and age were significant predictors of parasite species richness - significantly low at informal settlements and in the dry season and increasing with age of hosts. By contrast, neither site nor host age influenced parasite richness in $R$. norvegicus in Kuala Lumpur, Malaysia, yet parasite species richness in $R$. rattus, was higher at wet markets and in older rats. ${ }^{11}$

Prevalence of Gongylonema sp. in rodents was relatively high (25.3\%). A study in Kuala Lumpur found only $0.4 \%$ of $R$. rattus was infected (no R norvegicus) ${ }^{11}$; one study in India found $17.5 \%$ Rattus spp. infected ${ }^{9}$; and, one study in San Juan found 35\% Rattus spp. infected. ${ }^{33}$ Specimens will be identified to species level based on the gongylonemids in future work. Among 47 recognised species of Gongylonema, 15 are found in rodents, including G. neoplasticum and G. pulchrum. ${ }^{34}$ By 2013 there were 57 reported cases worldwide of human infections with Gongylonema spp. (and mostly assigned G. pulchrum), yet the first genetically confirmed case of G. pulchrum was in 2013. ${ }^{23}$ Infection is acquired through ingestion of infected intermediate hosts such as beetles or cockroaches, which in human cases, usually occurs unintentionally. ${ }^{34}$ Human gongylonemiasis creates the sensation of something moving in the buccal mucosa and some patients removed worms from their mouths..$^{35}$ Infected patients complained of reflux (which indicates possible involvement of the oesophagus ${ }^{35}$ ) and high fever with digestive disturbances and vomiting. ${ }^{36}$ Future work should combine genetic identification with morphology to identify the source of human infections and clarify the role that rats play in the transmission of this parasite. 
Trypanosoma lewisi had the second highest prevalence (22.8\%) among parasites reported in this study. Prevalence and intensity of infection were influenced by location, age, and gender with significantly more rats infected and with highest parasite burdens in the central business district in juveniles and in females. By contrast, prevalences ranged from $1.5 \%$ in Malaysia ${ }^{37}$ to $21.7 \%$ in Brazil. ${ }^{38}$ In the latter study, prevalence was highest in the wet season, in males and in young rats. Xenopsylla cheopis, the plague flea, is the common vector in warm climates ${ }^{39}$ (also the most prevalent on the rats in this study ${ }^{15}$ ), and infection is by ingestion of flea faeces or fleas. ${ }^{40}$ Two African studies, one in Nigeria and another in selected sites in three African countries (Tanzania, Swaziland and Namibia), found $75.7 \%{ }^{41}$ and $45.2 \%{ }^{42} R$. rattus respectively, infected with $T$. lewisi. This haemoflagellate can prove fatal in humans ${ }^{43}$ and in young rats. ${ }^{44}$ Human cases (often involving infants), have been reported from India, Thailand, Malaysia and Gambia. ${ }^{43}$ Common symptoms are fever, coughing, anorexia, depression and lassitude. ${ }^{43}$

Hymenolepis diminuta, a common cosmopolitan parasite of rats and mice, was the only parasite found in all three rodent species. This tapeworm has been found across the globe at prevalences of up to $66.7 \%$ in Rattus spp. ${ }^{45}$ Often, human cases in developing countries are incidentally reported when mass faecal parasite surveys in school children are carried out. Clinical case reports by 2004 were $<500$, with most cases in Southeast Asia probably due to the cultural practice of entomophagy ${ }^{46}$ We found that location, season and age group were significant predictors of both $H$. diminuta prevalence and worm abundance. Although $H$. diminuta has a relatively short prepatent period of 18-20 days, $R$. norvegicus pups were the least affected (prevalence $=3.8 \%$ ). Potential intermediate hosts for $H$. diminuta include fleas (Xenopsylla cheopis), and flour beetles (Tenebrio molitor) that are often found in grain storage facilities. ${ }^{6}$ The latter may explain the high prevalence of $H$. diminuta at the harbour and central business district. Significantly high infections after weaning in the wet season may occur because rats become independent and more likely to encounter abundant intermediate hosts while exploring and foraging.

Prevalence of Angiostrongylus cantonensis in R. norvegicus is the first from Africa. ${ }^{47}$ Rats are the definitive host, $A$. cantonensis does not occur naturally in other rodents. This nematode was first discovered in $R$. norvegicus and $R$. rattus in Canton (now Guangzhou), China in 1933,48 and has since been found globally. Location, season and age had significant effects on prevalence and worm abundance of $A$. cantonensis, where highest prevalence and abundance were in adults at informal settlements and urban/peri-urban areas during the wet season. These factors were probably mediated by the intermediate hosts - terrestrial snails and slugs - of $A$. cantonensis. In support, species of the snail families Achatinidae and Helicidae and slugs of the families Urocyclidae and Veronicellidae are more commonly found in sub-urban and rural areas than built-up city and harbour areas, especially in the wet season. ${ }^{49}$ Achatinids are eaten by humans in West Africa, ${ }^{50}$ yet information on snail-eating in southern Africa is lacking. Slime trails containing infective L1 larvae, left by molluscs on vegetables, are also a source of infection. ${ }^{51}$ By 2010, there were more than 2877 human case reports worldwide, the most common symptom being eosinophilic meningitis, but pathology varied from mild to severe, sometimes resulting in death. ${ }^{51}$ It is frequently encountered in humans in China and the Far East due to their penchant for strange and exotic culinary delicacies. ${ }^{52}$

Seroprevalence of the most ubiquitous parasite, $T$. gondii, was $11.3 \%$. One reason for the lack of statistical differences in the number of T. gondii-positive rats among location, season, or age groups could be because infections become established within seven days in the rodent host. Although cats, the definitive hosts of $T$. gondii, are common in informal settlements, the status of toxoplasmosis in these cats is not known, nor how inhabitants interact with them. Seroprevalence reports from Mozambique, Zimbabwe, Tanzania and South Africa ranged between 1-21.3\% in rodents and $4.1-51.2 \%$ in humans. ${ }^{14} \mathrm{~A}$ comprehensive review listed seroprevalences of $4-100 \%$ for women of child-bearing age in countries across the globe between 1990 and 2000.53 Humans can contract $T$. gondii by eating raw or undercooked flesh of various intermediate hosts, therefore human infections of T. gondii are not always related to rat infections..$^{53}$

Age of rodents was the only significant predictor for $M$. moniliformis prevalence (9.5\%), as pups are much less likely to be infected than adults due to the five-week prepatent period of the parasite. This "thorny-headed worm" was described from $R$. rattus and $R$. norvegicus in Egypt $^{54}$ yet is rare in southern Africa. Prevalence of $M$. moniliformis in the gut of Rattus spp. from across the globe range between $0 \%$ and $59.3 \% .^{8}$ There have been clinical case reports of $M$. moniliformis infections in people from Australia, Asia, Europe, America and Africa (Sudan, Nigeria, Egypt, Madagascar and Zimbabwe). ${ }^{55,56}$ In Ghana, West Africa, larval stages of $M$. moniliformis were found in the intermediate host, Periplaneta americana. ${ }^{57}$ There is evidence that worm abundance is positively correlated with abundance of common arthropod intermediate hosts, particularly in the hot, humid rainy season..$^{58}$ Although we found no evidence for the influence of season on prevalence, worm abundance was significantly high during the wet season at harbour and informal settlement sites.

Calodium hepaticum was present in male and female $R$. norvegicus in both seasons at both the harbour $(n=3)$ and urban/peri-urban $(n=7)$, and one M. natalensis (U/PU, dry season) had a severe liver infection. Transmission of parasite eggs is facilitated mainly by cannibalism and necrophagy, particularly inside burrows; and, once eggs mature to the infective stage, allogrooming can cause re-infection. ${ }^{59,60}$ We found no evidence that prevalence and intensity were related to season or gender of the host. Low prevalence of $C$. hepaticum may be due to the relatively mild winters and abundant food resources throughout the year in Durban, which, in turn, may result in low levels of cannibalism and necrophagy. Human hepatic capillariasis is a serious infection that is usually diagnosed at autopsy, yet there were only two clinical cases and one autopsy reported from South Africa between 1957 and 1973. ${ }^{61-63}$

Hymenolepis nana was found only in three rats at the harbour in the wet season. This tapeworm needs only one host to complete its lifecycle. ${ }^{64}$ Eggs are infective when they leave the gravid segments and can infect the same host by anus-hand-mouth contamination or via oncospheres hatching from eggs laid in the gut, or from another host via eggs in contaminated food. Previous studies have estimated $H$. nana prevalence in $R$. norvegicus between $0 \%$ and $42.4 \%{ }^{32,65}$; reports have been varied in humans. For example, low prevalences in school-based surveys where infected children were symptomless, ${ }^{66,67}$ and individual symptomatic cases in children from disadvantaged backgrounds as a concomitant infection with Giardia intestinalis, ${ }^{68}$ or in immunocompromised patients together with Crytosporidium parvum. ${ }^{69}$

The most common mechanically transmitted eggs carried by $R$. norvegicus in this study belonged to Ascaris sp. (probably $A$. lumbricoides). Infected rats were caught, mainly at urban/peri- 
urban sites; almost half of the carrier rats were caught under a wooden hut that was used as a crèche. Previously, children in informal settlements of eThekwini exhibited high prevalence of $A$. lumbricoides (81.7-96.3\%). ${ }^{70}$ It is perhaps notable that $39 \%$ of boys and $53 \%$ of girls in northern KwaZulu-Natal regularly ate soil. ${ }^{71}$

\section{Conclusions}

All eight parasites identified in this study are of public health importance and capable of causing pathology, with C. hepaticum the most serious and $H$. diminuta the least. Although prevalences of parasites were relatively low, the mere presence of these parasites merits further investigation in eThekwini as well as other metropolitan areas in Africa. We found evidence that location, season, rat age and gender differentially affected the prevalence and mean worm abundance of parasite species. However, one caveat of this study is that it was not possible to design the sampling protocol ourselves, especially in the slums, partly because of the high crime rates. Thus sampling effort was not consistent and equal across locations and seasons, which may have affected our statistical analyses of parasite prevalence and abundance. Future work should standardise the sampling effort and replicate sampling in other urban landscapes, to better understand the patterns and drivers of parasite loads in rats in African urban landscapes.

Acknowledgements - We are endebted to Mr. Sagren Moodley and his Vector Control Team at the Department of Health, eThekwini, for trapping of the rodents for this project. Special thanks go to Ms Karen Hope for help in the laboratory during the processing of the euthanased rodents, to Ms Theshnie Naidoo for help with the genetics work, to Ms Yashodini Pillay and Ms Danica Naidoo who assisted in removing the helminths from the rodent guts and to Ms Naidoo for sexing and counting the worms.

Conflict of Interest - The authors declare that they do not have a commercial or any other association which might pose a conflict of interest.

\section{References}

1. Karagas KA. Disease. In: Northrup CC, editor. Encyclopaedia of world trade from ancient times to the present Volumes 1-4. London: Routledge; 2015. p. 278-80.

2. Holsendorf BE. Rat harborage and ratproofing. Public Health Reports (1896-1970). 1937;52(3):75-81. http://dx.doi.org/10.2307/4582061

3. Taylor PJ, Arntzen L, Hayter M, et al. Understanding and managing sanitary risks due to rodent zoonoses in an African city: beyond the Boston Model. Integrative Zoology 2008;3(1):38-50.http://dx.doi. org/10.1111/inz.2008.3.issue-1

4. Donaldson $\mathrm{HH}$. On the control of the rat population. Science, New Series. 1925;61(1577):305-6.

5. Jassat W, Naicker N, Naidoo $\mathrm{S}$, et al. Rodent control in urban communities in Johannesburg, South Africa: from research to action. Int J Environ Health Res. 2013;23(6):474-83. http://dx.doi.org/10.108 0/09603123.2012.755156

6. El-Sherbini GT, El-Sherbini ET. The role of cockroaches and flies in mechanical transmission of medical important parasites. J Entomol Nematol. 2011;3(7):98-104.

7. Kataranovski D, Kataranovski M, Deljanin I. Helminth fauna of Rattus norvegicus Berkenhout, 1769 from the Belgrade area, Serbia. Serbia. Arch Biol Sci. 2010;62(4):1091-100.http://dx.doi.org/10.2298/ABS1004091K

8. Bonfante R, Faust EC, Giraldo LE. Parasitologic surveys in Cali, Departmento Del Valle, Colombia. IX. Endoparasites of rodents and cockroaches in Ward Siloe, Cali, Colombia. J Parasitol. 1961;47(5): 843-6. http://dx.doi.org/10.2307/3275485

9. Paramasvaran S, Sani RA, Hassan L, et al. Endo-parasite fauna of rodents caught in five wet markets in Kuala Lumpur and its potential zoonotic implications. Trop Biomed. 2009;26(1):67-72.
10. Garedaghi Y, Khaki AA. Prevalence of gastrointestinal and blood parasites of rodents in Tabriz, Iran, with emphasis on parasitic zoonoses. Crescent J Med Biol Sciences. 2014;1(1):9-12.

11. Mohd Zain SN, Behnke JM, Lewis JW. Helminth communities from two urban rat populations in Kuala Lumpur, Malaysia. Malaysia. Parasit Vectors. 2012;5(1):47.http://dx.doi.org/10.1186/1756-3305-5-47

12. Mafiana CF, Osho MB, Sam-Wobo S. Gastrointestinal helminth parasites of the black rat (Rattus rattus) in Abeokuta, southwest Nigeria. J Helminth. 1997;71(03):217-20. http://dx.doi.org/10.1017/ S0022149X00015947

13. Onyenwe IW, Ihedioha JI, Ezeme RI. Prevalence of zoonotic helminths in local house rats (Rattus rattus) in Nsukka, Eastern Nigeria. Animal Res Internat. 2009;6(3):1040-4.

14. Belmain SR. Rats and Human Health in Africa: Proceedings of an international workshop on rodent-borne diseases and the RatZooMan research project. RatZooMan Workshop; 2006 May 3-6; Malelane, Republic of South Africa: Natural Resources Institute; 2006. p. 1-46.

15. Hope KJ. Ectoparasites of Rattus norvegicus (Berkenhout, 1769) in the eThekwini Municipality District, KwaZulu-Natal, South Africa [Masters Dissertation]. Durban: University of KwaZulu-Natal; 2011.

16. Gannon WL, Sikes RS, the Animal Care and Use Committee of the American Society of Mammalogists. Guidelines of the American society of mammalogists for the use of wild mammals in research. J Mammal. 2007;88(3):809-23. http://dx.doi.org/10.1644/06-MAMM-F-185R1.1

17. Lynch MJ, Raphael SS, Mellor LD, et al. Medical laboratory technology and clinical pathology. 2nd ed.. Philadelphia, PA: W.B. Saunders Company; 1969. 644 p.

18. Allen AVH, Ridley DS. Further observations on the formol-ether concentration technique for faecal parasites. J Clin Pathol 1970;23(6):545-6. http://dx.doi.org/10.1136/jcp.23.6.545

19. Hirata DN, Nass RD. Growth and sexual maturation of laboratoryreared, wild rattus norvegicus, R. rattus and R. exulans in Hawaii. J Mammal. 1974;55(2):472-4. http://dx.doi.org/10.2307/1379024

20. Leirs H,StuyckJ,Verhagen R, etal.Seasonal variation in growth of Mastomys natalensis (Rodentia: Muridae) in Morogoro, Tanzania. Tanzania. Afr J Ecol. 1990;28:298-306. http://dx.doi.org/10.1111/j.1365-2028.1990.tb01164.x

21. Hoare CA. The trypanosomes of mammals. A zoological monograph. Oxford: Blackwell Scientific Publications; 1972.

22. Cleave HJ. Speciation and formation of genera in acanthocephala. Syst Zool. 1952;1(2):72-83. http://dx.doi.org/10.2307/2411367

23. Allen JE. Gongylonema pulchrum infection in a resident of Williamsburg, Virginia, verified by genetic analysis. Am J Trop Med Hyg. 2013;89(4):755-7. http://dx.doi.org/10.4269/ajtmh.13-0355

24. Mackerras MJ, Sandars DF. The life history of the rat lung-worm, Angiostrongylus cantonensis (Chen) (Nematoda: Metastrongylidae). Aust J Zool. 1955;3:1-21. http://dx.doi.org/10.1071/ZO9550001

25. Thompson JD, Higgins DG, Gibson TJ. CLUSTAL W: improving the sensitivity of progressive multiple sequence alignment through sequence weighting, position-specific gap penalties and weight matrix choice. Nucleic Acids Res. 1994;22(22):4673-80. http://dx.doi. org/10.1093/nar/22.22.4673

26. Swofford DL. PAUP* Phylogenetic analysis using parsimony (*and other methods). Version 4. Sunderland, MA: Sinauer Associates; 2002. Available from: http://paup.csit.fsu.edu.

27. Posada D. jModelTest: Phylogenetic model averaging. Mol Biol Evol. 2008;25: 1253-6. http://dx.doi.org/10.1093/molbev/msn083

28. Cracraft J. Species concepts and speciation analysis. Current Ornithology. 1983;1(7): 159-87. http://dx.doi.org/10.1007/978-1-4615-6781-3

29. TheFree Dictionary by Farlex. [cited 2016Aug 29];Available from:http:// medical-dictionary.thefreedictionary.com/mechanicaltransmission.

30. Kamiya M, Fukumoto SI. Angiostrongylus sandarsae Alicata, 1968 (Nematoda: Metastrongyloidea) from Praomys natalensis in Kenya. Jpn J Vet Res. 1988;36:47-52.

31. Alicata JE. Angiostrongylus sandarsae sp. n. (Nematoda: Metastrongyloidea), a Lungworm of Rodents in Mozambique, East Africa. J Parasitol. 1968;54(5):896-9. http://dx.doi.org/10.2307/3277116

32. Luttermoser GW. A helminthological survey of baltimore house rats (Rattus norvegicus). Am J of Epidemiol. 1936;24:350-60.

33. de Leon DD. Helminth parasites of rats in San Juan, puerto rico. Puerto Rico. J Parasitol. 1964;50(3):478-9. http://dx.doi.org/10.2307/3275862 
34. Kinsella JM, Robles M, Preisser WC. A review of Gongylonema spp. (Nematoda: Gongylonematidae) in North American rodents with description of a new species from the cotton rat, Sigmodon hispidus (Mammalia: Cricetidae). Zootaxa. 2016;4107(2):277-84. http://dx.doi.org/10.11646/zootaxa.4107.2

35. Eberhard ML, Busillo C. Human Gongylonema infection in a resident of New York City. Am J Trop Med Hyg. 1999;61(1):51-2.

36. Ward HB. Gongylonema in the role of a human parasite. J Parasitol. 1916;2(3):119-25. http://dx.doi.org/10.2307/3271194

37. Siti Shafiyyah CO, Jamaiah I, Rohela $M$, et al. Prevalence of intestinal and blood parasites among wild rats in Kuala Lumpur. Malaysia. Trop Biomed. 2012;29(4):544-50.

38. Linardi PM, Botelho JR. Prevalence of trypanosoma lewisi in rattus norvegicus from Belo Horizonte, State of Minas Gerais, Brazil. Brazil. Mem Inst Oswaldo Cruz. 2002;97(3):411-4. http://dx.doi.org/10.1590/ S0074-02762002000300024

39. Bitam I, Dittmar K, Parola P, et al. Fleas and flea-borne diseases. Int J Infect Dis. 2010;14(8):e667-76. http://dx.doi.org/10.1016/j.ijid.2009.11.011

40. Jittapalapong S, Herbreteau V, Hugot JP, et al. Review: Relationship of Parasites and Pathogens Diversity to Rodents in Thailand. Kasetsart J Nat Sci. 2009;43:106-17.

41. Akinboade OA, Dipeolu OO, Ogunji FO, et al. The parasites obtained and bacteria isolated from house rats (Rattus rattus Linnaeus, 1758) caught in human habitations in Ibadan. Nigeria. Int J Zoonoses. 1981;8(1):26-32.

42. Katakweba AAS, Mulungu LS, Eiseb SJ, et al. Prevalence of haemoparasites, leptospires and coccobacilli with potential for human infection in the blood of rodents and shrews from selected localities in Tanzania, Namibia and Swaziland. Afr Zoo. 2012;47(1):119-27. http://dx.doi.org/10.3377/004.047.0112

43. Truc $P$, Büscher $P$, Cuny $G$, et al. Atypical human infections by animal trypanosomes. PLos Negl Trop Dis. 2013;7(9):e2256. http://dx.doi. org/10.1371/journal.pntd.0002256

44. Mac Neal WJ. The life-history of trypanosoma lewisi and trypanosoma brucei. J Infect Dis. 1904;1(4):517-43. http://dx.doi.org/10.1093/ infdis/1.4.517

45. Claveria FG, Causapin J, de Guzman MA, et al. Parasite diversity in Rattus spp. Caught in wet markets. Southeast Asian J Trop Med Public Health. 2005;36(4):146-8.

46. Wiwanitkt V. Overview of Hymenolepis diminuta infection among Thai patients. Medscape Gen Med. 2004;6(2):7.

47. Archer $\mathrm{CE}$, Appleton CC, Mukaratirwa $S$, et al. The rat lung-worm Angiostrongylus cantonensis: A first report in South Africa. S Afr Med J. 2011;101(3):174-5. http://dx.doi.org/10.7196/SAMJ.4309

48. Chen HT. Un nouveau nématode pulmonaire, Pulmonema contonensis n.g., n.sp., des rats de Canton. Annales Parasitol. 1935;3:312-7.

49. Herbert D, Kilburn D. Field Guide to the land snails and slugs of eastern South Africa. Pietermaritzburg: Natal Museum; 2004.

50. Ukpong SU. Snail (Archachatina marginata) pie: a nutrient rich snack for school-age children and young mothers. Int. J. Food Safety, Nutrit Pub Health. 2009;2(2):125-30.

51. Wang QP, Wu ZD, Wei J, et al. Human Angiostrongylus cantonensis: an update. Eur J Clin Microbiol Infect Dis. 2012;31(4):389-95. http://dx.doi.org/10.1007/s10096-011-1328-5

52. Wang $Q P$, Lai $D H$, Zhu $X Q$, et al. Human angiostrongyliasis. Lancet Infect Dis. 2008;8(10):621-30. http://dx.doi.org/10.1016/S14733099(08)70229-9
53. Tenter AM, Heckeroth AR, Weiss LM. Toxoplasma gondii: from animals to humans. Int J Parasitol. 2000;30(12-13):1217-58. http://dx.doi. org/10.1016/S0020-7519(00)00124-7

54. Ward HL, Nelson DR. Acanthocephala of the genus moniliformis from rodents of Egypt with the description of a new species from the Egyptianspinymouse(Acomys cahirinus).JParasitol. 1967;53(1):150-6. http://dx.doi.org/10.2307/3276638

55. Bettiol S, Goldsmid JM. A case of probable imported moniliformis moniliformis infection in Tasmania. J Travel Med. 2000;7:336-7.

56. Goldsmid JM, Ewart Smith ME, Fleming F. Human infection with Moniliformis sp. in Rhodesia. AnnTropMed Parasitol. 1974;68(3):363-4. http://dx.doi.org/10.1080/00034983.1974.11686960

57. Southwell T. Notes on the larvae of moniliformis moniliformis (Brems.) found in African cockroaches. J Parasitol. 1922;9(2):99-101. http://dx.doi.org/10.2307/3271142

58. Tanaka LK, Tanaka SK. Rainfall and seasonal changes in arthropod abundance on aTropicalOceanic Island. Biotropica. 1982;14(2):114-23. http://dx.doi.org/10.2307/2387740

59. Spratt DM, Singleton GR. Studies on the life-cycle, infectivity and clinical effects of capillaria-hepatica (Bancroft) (Nematoda) in Mice, mus-musculus. Mus musculus. Aus J Zool. 1986;34:663-75. http://dx.doi.org/10.1071/ZO9860663

60. Farhang-Azad A. Ecology of capillaria hepatica (Bancroft 1893) (Nematoda). II. Egg-releasing mechanisms and transmission. J Parasitol. 1977;63(4):701-6. http://dx.doi.org/10.2307/3279576

61. Cochrane JC, Sagorin L, Wilcocks MG. Capillaria hepatica Infection in Man. S Afr Med J. 1957;31(30):751-5.

62. Silverman NH, Katz JS, Levin SE. Capillaria hepatica Infestation in a Child. S Afr Med J. 1973;47(6):219-21.

63. Kallichurum S, Elsdon-Dew R. Capillaria in man. A case report. S Afr Med J. 1961;35:860-1.

64. Beaver PC, Jung RC, Cupp EW. Clinical Parasitology. 9th ed. Philadelphia, PA: Lea \& Febiger; 1984. p. 509-11.

65. Schiller EL. Studies on the helminth fauna of alaska. V. notes on adak rats (Rattus norvegicus Berkenhout) with special reference to helminth parasites. J Mammal. 1952;33(1):38-49. http://dx.doi. org/10.2307/1375639

66. Siwila J, Phiri IG, Enemark HL, et al. Intestinal helminths and protozoa in children in pre-schools in Kafue district, Zambia. Zambia. Trans Soc Trop Med Hyg. 2010;104(2):122-8. http://dx.doi.org/10.1016/j. trstmh.2009.07.024

67. Van Niekerk $\mathrm{CH}$, Weinberg EG, Lorn Shore SC, et al. Intestinal parasitic infestation in urban and rural Xhosa children. A comparative Study. $S$ Afr Med J. 1979:55(19):756-7.

68. Paola M, Brandonisio O, Carito V, et al. Hymenolepis nana parasites in adopted children. Clin Infect Dis. 2005;41:571-2.

69. Meamar AR, Rezaian M, Mohraz M, et al. Concomitant severe infection with crytosporidium parvum and hymenolepis nana in an AIDS patient. Indian J Med Sci. 2007;61(7):418-9. http://dx.doi.org/10.4103/0019-5359.33192

70. Appleton CC, Mosala TI, Levin J, et al. Geohelminth infection and reinfectionafterchemotherapyamongslum-dwellingchildreninDurban, South Africa. South Africa. AnnTropMed Parasitol. 2009;103(3):249-61. http://dx.doi.org/10.1179/136485909X398212

71. SaathoffE, Olsen A, Kvalsvig JD, et al. Geophagy and its association with geohelminth infection in rural schoolchildren from northern KwaZuluNatal, South Africa. Trans R Soc Trop Med Hyg. 2002;96(5):485-90. http://dx.doi.org/10.1016/S0035-9203(02)90413-X 